PAPER

Impurity-free quantum well intermixing for large optical cavity high-power laser diode structures

To cite this article: Abdullah Kahraman et al 2016 Semicond. Sci. Technol. 31085013

View the article online for updates and enhancements.
Related content

- $\frac{\text { Conservation of quantum efficiency in }}{\text { quantum well intermixing by stress }}$
$\frac{\text { engineering with dielectric bilayers }}{\text { Seval Arslan, Abdullah Demir, Seval ahin }}$
et al.
- Investigations of impurity-free vacancy
$\frac{\text { disordering in (Al)InGaAs(P)/InGaAs }}{\text { quantum wells }}$
S C Du, L Fu, H H Tan et al.
- Quantum well intermixing
J H Marsh

Recent citations

- Conservation of quantum efficiency in
quantum well intermixing by stress
engineering with dielectric bilavers
Seval Arslan et al 


\title{
Impurity-free quantum well intermixing for large optical cavity high-power laser diode structures
}

\author{
Abdullah Kahraman ${ }^{1}$, Emre Gür ${ }^{2}$ and Atilla Aydını ${ }^{1}$ \\ ${ }^{1}$ Department of Physics, Bilkent University, Ankara, 06800, Turkey \\ ${ }^{2}$ Department of Physics, Faculty of Science, Atatürk University, Erzurum, 25240, Turkey \\ E-mail: aydinli@fen.bilkent.edu.tr
}

Received 15 February 2016, revised 8 June 2016

Accepted for publication 10 June 2016

Published 21 July 2016

\begin{abstract}
We report on the correlation of atomic concentration profiles of diffusing species with the blueshift of the quantum well luminescence from both as-grown and impurity free quantum wells intermixed on actual large optical cavity high power laser diode structures. Because it is critical to suppress catastrophic optical mirror damage, sputtered $\mathrm{SiO}_{2}$ and thermally evaporated $\mathrm{SrF}_{2}$ were used both to enhance and suppress quantum well intermixing, respectively, in these ( $\mathrm{Al})$ GaAs large optical cavity structures. A luminescence blueshift of $55 \mathrm{~nm}(130 \mathrm{meV})$ was obtained for samples with $400 \mathrm{~nm}$ thick sputtered $\mathrm{SiO}_{2}$. These layers were used to generate point defects by annealing the samples at $950{ }^{\circ} \mathrm{C}$ for $3 \mathrm{~min}$. The ensuing $\mathrm{Ga}$ diffusion observed as a shifting front towards the surface at the interface of the GaAs cap and AlGaAs cladding, as well as $\mathrm{Al}$ diffusion into the GaAs cap layer, correlates well with the observed luminescence blue shift, as determined by $\mathrm{x}$-ray photoelectron spectroscopy. Although this technique is well-known, the correlation between the photoluminescence peak blue shift and diffusion of $\mathrm{Ga}$ and $\mathrm{Al}$ during impurity free quantum well intermixing on actual large optical cavity laser diode structures was demonstrated with both $\mathrm{x}$ ray photoelectron and photoluminescence spectroscopy, for the first time.
\end{abstract}

Keywords: quantum well intermixing, $\mathrm{AlGaAs} / \mathrm{GaAs}$ laser diode, diffusion of Ga

(Some figures may appear in colour only in the online journal)

\section{Introduction}

There is a continuous demand for ever higher power and efficiency from semiconductor lasers. State-of-the-art high power lasers require not only sophisticated design but also complex fabrication technologies to push the boundaries. A major obstacle to higher power is catastrophic optical mirror damage (COMD) that occurs at the mirrors of the cavity [1]. Even when the near mirror regions are not electrically pumped, effectively dividing the optical cavity into passive and active regions, mirror damage takes place due to light absorption by interface states between the cleaved facet and coated multilayer dielectric mirror that leads to non-radiative recombination causing the generation of heat. This large quantity of heat in a small facet surface can lead to local reduction of the band gap and COMD [2]. Reduction of the band gap causes further light absorption where a positive feedback develops accelerating COMD and suddenly exceeding the damage threshold [3].

Among several approaches to improve facet stability and increase the threshold for damage, two classical approaches are taken: increase the facet surface area to reduce the power density incident on the mirrors and manipulate the local band gap near the mirrors to reduce re-absorption of light generating non-radiative recombination [4]. One approach to modify the band gap at the cavity edges is to use etch-back and epitaxial regrowth or overgrowth of the wider band gap material for the quantum well. This leads to a higher facet damage threshold and the output power and electro-optical conversion efficiency is limited around $15 \mathrm{~W}$ and $60 \%$, respectively [5, 6]. However, etch-back and regrowth at the passive waveguide sections of a laser cavity is both tedious 
and expensive. It further has a coupling efficiency problem at the interface between the active and passive sections of the waveguide. On the other hand, control of the band gap near the facets can also be achieved by impurity induced disordering (IID), impurity free vacancy disordering (IFVD), and laser-induced disordering (LID) [7]. The IID technique is effective, but leads to free carrier absorption due to the introduction of unwanted carriers. The structure of modern lasers employing quantum wells, to generate light, surrounded by large band gap and low index waveguides and claddings gives the opportunity to intermix the quantum well using IFVD, changing its compositional profile and increasing the effective band gap close to cavity edges during fabrication. In this approach, the creation of a non-absorbing mirror (NAM) where the facet is almost transparent leads to high COMD thresholds for higher power extraction and a longer lifetime. Due to these advantages, IFVD quantum well intermixing (QWI) is preferred due to lower loss and higher optical coupling efficiency when compared with IID and selective epitaxial growth techniques [8].

Work on IFDV-based QWI as a matter studying interface stability has been performed early on [9]. Selective intermixing of several quantum wells separated with $\mathrm{Al}_{0.22} \mathrm{Ga}_{0.78} \mathrm{As}$ barriers on a semi-insulating substrate was studied using $\mathrm{SiO}_{2}$ cap layers. Band gap shifts of up to $90 \mathrm{meV}$ at $1100{ }^{\circ} \mathrm{C}$ for $15 \mathrm{~s}$ was found to increase with thicker oxide layers. Studies on the influence of parameters of plasma-enhanced chemical vapor deposition of $\mathrm{SiO}_{2}$ on the band gap shift has shown that the nature of the dielectric layer influences the degree of intermixing [10]. Starting with oxidation of the GaAs cap layer in order to form $\mathrm{Ga}_{2} \mathrm{O}_{3}$ to enhance the intermixing, and using $\mathrm{Al}$ overlayers on $\mathrm{Ga}_{2} \mathrm{O}_{3}$ to inhibit the intermixing by reduction of $\mathrm{Ga}_{2} \mathrm{O}_{3}$, many experiments have been done to control the encapsulant layer properties such as exposing deposited $\mathrm{SiO}_{2}$ layers to oxygen $[11,12]$, varying $\mathrm{SiH}_{4}$ flow rate [13], and varying the $\mathrm{N}_{2} \mathrm{O}$ flow rate during chemical vapor deposition of $\mathrm{SiO}_{2}$ [14]. Effects of strain on the degree of intermixing has also been studied. Controlled addition of $\mathrm{P}_{2} \mathrm{O}_{5}$ into $\mathrm{SiO}_{2}$ has been used to control the extent of strain and its influence on the quantum well emission has been documented [15]. The role of stress in the inter-diffusion of $\mathrm{Ga}$ has been elucidated upon by several groups [16, 17]. Patterned $\mathrm{Si}_{3} \mathrm{~N}_{4}$ layers covered with $\mathrm{SiO}_{2}$ and patterned $\mathrm{SiO}_{2}$ layers covered with $\mathrm{Si}_{3} \mathrm{~N}_{4}$ have been shown to have opposing effects on the intermixing leading to the idea of directed diffusion of point defects such as $\mathrm{Ga}$ vacancies. Layer disordering is inhibited in the $\mathrm{SiO}_{2} / \mathrm{Si}_{3} \mathrm{~N}_{4}$ capped areas while it is enhanced in the $\mathrm{Si}_{3} \mathrm{~N}_{4} / \mathrm{SiO}_{2}$ capped areas. Selective intermixing requires that the remaining surface area of the device undergo minimal or no intermixing. This is done with the use of layers that inhibit intermixing. Various type of layers such as photoresists [18], $\mathrm{WN}_{\mathrm{x}}$ [19], and $\mathrm{SrF}_{2}$ [20], were used to inhibit the intermixing. A comparative and systematic study of the influence of $\mathrm{SiO}_{2}$ and $\mathrm{SrF}_{2}$ on QWI as capping material for $\mathrm{AlGaAs} / \mathrm{GaAs}$ quantum well structures have yielded $\mathrm{Al}$ diffusion coefficients of $2.1 \times 10^{-15} \mathrm{~cm}^{2} \mathrm{~s}^{-1}$ and $4.0 \times 10^{-17} \mathrm{~cm}^{2} \mathrm{~s}^{-1}$ for $\mathrm{SiO}_{2}$ and $\mathrm{SrF}_{2}$ caps, respectively [20].
Intermixing on atomic species can be tracked using depth resolved spectroscopies such as secondary ion mass spectroscopy (SIMS), x-ray photoelectron spectroscopy (XPS) and Rutherford backscattering spectroscopy (RBS), among others. In previous work on QWI, SIMS [21, 22], RBS [23], X-ray photoelectron spectroscopy (XPS) [11], and proton induced X-ray emission has been used [24]. Earlier work has been done on doped bulk GaAs [24, 25] and on single and multi-quantum wells grown on GaAs substrates solely to study diffusion [26]. Although many studies on IFVD QWI with standard low power structures have been performed, little work has been performed on actual large optical cavity (LOC) high power laser diode structures in AlGaAs/GaAs material systems [27]. The thickness of the $\mathrm{SiO}_{2}$ layer was only $200 \mathrm{~nm}$ and the distance between $\mathrm{SiO}_{2}$ and QW was 1.425 micron. A maximum $70 \mathrm{~nm}$ shift was obtained at $960{ }^{\circ} \mathrm{C}$ annealing temperature for the duration of $90 \mathrm{~s}$.

In this work, the correlation of band gap widening and $\mathrm{Ga}$ and $\mathrm{Al}$ diffusion results of QWI in actual large optical cavity (LOC) diode structures is reported for the first time. Both $\mathrm{SiO}_{2}$ and $\mathrm{SrF}_{2}$ were used to enhance and inhibit the intermixing of the GaAs quantum well of a HPLD structure, respectively. The effects of the encapsulant thickness as well as the annealing conditions (temperature and time) have been investigated systematically by low temperature photoluminescence spectroscopy. Depth resolved XPS was used to study the diffusion of atomic species in the intermixed sample. We find that despite the thick cladding layers of a large cavity high power laser diode, we clearly observe significant $\mathrm{Ga}$ outdiffusion that, along with $\mathrm{Al}$, correlates well with observed PL data.

\section{Experimental}

The LOC single quantum well HPLD structure was grown by metal-organic chemical vapor deposition on a 2-inch n-type doped with Si $1-3 \times 10^{18} \mathrm{~cm}^{-3}$ (100) GaAs substrate. A $12 \mathrm{~nm}$ undoped GaAs quantum well is embedded in $200 \mathrm{~nm}$ undoped $\mathrm{Al}_{0.37} \mathrm{Ga}_{0.63} \mathrm{As}$ waveguide layers. Between a $1.550 \mu \mathrm{m} \mathrm{p}-\mathrm{Al}_{0.55} \mathrm{Ga}_{0.45} \mathrm{As}$ upper cladding layer and upper waveguide layer, a $100 \mathrm{~nm}$ undoped $\mathrm{Al}_{0.55} \mathrm{Ga}_{0.45}$ As layer is placed. A $1.55 \mu \mathrm{m}$ lower cladding layer $\left(\mathrm{n}-\mathrm{Al}_{0.55} \mathrm{Ga}_{0.45} \mathrm{As}\right)$ is placed between the GaAs substrate and a $400 \mathrm{~nm}$ GaAs buffer layer. The distance between surface and quantum well is $2.35 \mu \mathrm{m}$ including the $500 \mathrm{~nm}$ GaAs cap layer, as shown in table 1. The dopant used for the p-type AlGaAs cladding layer is $\mathrm{Zn}\left(1 \times 10^{18} \mathrm{~cm}^{-3}\right)$ and for the n-type AlGaAs cladding layer is $\mathrm{Si}\left(1 \times 10^{18} \mathrm{~cm}^{-3}\right)$. For the $\mathrm{n}$-type and the p-type GaAs buffer and cap layers, respectively, dopants are $\mathrm{Si}$ $2 \times 10^{18} \mathrm{~cm}^{-3}$ and $\mathrm{Zn}>4 \times 10^{19} \mathrm{~cm}^{-3}$. In order to study the effects of different process parameters such as dielectric thickness, annealing time and temperature on intermixing, the 2-inch wafer was cut into small pieces, some used as asgrown and others as samples intermixed under different process conditions. They were then compared both optically and chemically using elemental analysis through XPS depth profiling. 
Table 1. Epitaxial structure of the high power laser diode used in this study. $\mathrm{SiO}_{2}$ and $\mathrm{SrF}_{2}$ are deposited on top of the $500 \mathrm{~nm}$ thick GaAs cap layer. Epitaxial structure is shown on the right side of the plot. Abbreviations used in the epitaxial structure are clad; cladding, WG; waveguide.

\begin{tabular}{|c|c|c|c|c|c|}
\hline Layer & Material & $\begin{array}{l}\text { Mole } \\
\text { fraction, } \\
x\end{array}$ & $\begin{array}{l}\text { Thickness } \\
\mu \mathrm{m}\end{array}$ & & \\
\hline 9 & $\mathrm{SiO}_{2} / \mathrm{SrF}_{2}$ & - & $0.4 / 0.2$ & $\mathrm{SiO}_{2} / \mathrm{SrF}_{2}$ & $400 \mathrm{~nm}$ \\
\hline 8 & GaAs & - & 0.5 & GaAs cap & $500 \mathrm{~nm} Z \mathrm{Zn}:>4 \times 10^{19} \mathrm{~cm}^{-3}$ \\
\hline 7 & $\mathrm{Al}(\mathrm{x}) \mathrm{GaAs}$ & 0.55 & 1.55 & $\mathrm{Al}_{0.55} \mathbf{G a}_{0.45}$ As clad & $1550 \mathrm{~nm} \mathrm{Zn}: 1 \times 10^{18} \mathrm{~cm}^{-3}$ \\
\hline 6 & $\mathrm{Al}(\mathrm{x}) \mathrm{GaAs}$ & 0.55 & 0.1 & $\mathrm{Al}_{0.55} \mathrm{Ga}_{0,0 \mathrm{As}} \mathrm{As}$ clad & $100 \mathrm{~nm} \quad$ uid \\
\hline$\frac{5}{4}$ & $\frac{\mathrm{Al}(\mathrm{x}) \mathrm{GaAs}}{\mathrm{GaAs}}$ & 0.37 & $\frac{0.2}{0.012}$ & 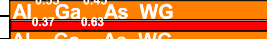 & $200 \mathrm{~nm}$ GGAS QWW-12 $\mathrm{nm}$ \\
\hline 3 & $\mathrm{Al}(\mathrm{x}) \mathrm{GaAs}$ & 0.37 & 0.2 & & \\
\hline 2 & $\mathrm{Al}(\mathrm{x}) \mathrm{GaAs}$ & 0.55 & 1.55 & $\mathrm{Al}_{0.55} \mathrm{Ga}_{0.45}$ As clad & $1550 \mathrm{~nm}$ Si: $1 \times 10^{18} \mathrm{~cm}^{-3}$ \\
\hline 1 & GaAs & - & 0.4 & GaAs 400 nm & $S i: 2 \times 10^{18} \mathrm{~cm}^{-3}$ \\
\hline & \multicolumn{3}{|c|}{ GaAs substrate } & (100) GaAs substrate & Si: $1-3 \times 10^{18} \mathrm{~cm}^{-3}$ \\
\hline
\end{tabular}

Thin layers of $\mathrm{SiO}_{2}$ ranging in thickness from 200 to $400 \mathrm{~nm}$ were deposited on LOC HPLD structures by RF sputtering (Leybold L 560 system) under $4 \times 10^{-6}$ torr, $200 \mathrm{sccm}$ Ar gas flowing corresponding to 10 mTorr growth pressure with RF power of $100 \mathrm{~W}$ to induce out-diffusion of $\mathrm{Ga}$ and $\mathrm{Al}$ atoms. Suppression of QWI was achieved by $100 \mathrm{~nm}$ thick $\mathrm{SrF}_{2}$ layers deposited by thermal evaporation. Rapid thermal processing (RTP) was used to carry out diffusion of defects at high temperatures (AG associates minipulse series). During RTP, samples were sandwiched between fresh GaAs wafers in order to prevent loss of As. In order to understand the QWI effect on the optical properties of LOC HPLDs, photoluminescence (PL) measurements were performed after every process. The PL measurements were performed at low temperature $(6 \mathrm{~K})$ using cryostat (Cryo industries). $\mathrm{Ar}^{+}$gas laser (at $514.5 \mathrm{~nm}$ line) was used as the excitation source and the luminescence from the samples were focused on to a $1 \mathrm{~m}$ Jobin Yvon double grating monochromator system (Horiba Spectralink U1000) coupled to a cooled charge-coupled device (CCD) detection system. In order to understand the diffusion of the $\mathrm{Ga}, \mathrm{Al}$, As, atoms, depth resolved XPS measurements were carried out on the asgrown and thermally processed samples using an XPS system (PHI 5000 VersaProbe) employing a monochromated Al K $\mathrm{X}$-ray source equipped with an Ar-ion gun for in-depth profiling.

\section{Results and discussion}

Figure 1 shows the effects of varying the annealing duration, temperature and encapsulant thickness on the QWI through photoluminescence signature of the quantum wells. All of the PL measurements were performed at $6 \mathrm{~K}$. Figure 1(a) illustrates the annealing temperature dependence of the PL spectra of LOC HPLD structures due to QWI. Samples with $200 \mathrm{~nm}$ sputtered $\mathrm{SiO}_{2}$ were annealed at $850,900,950{ }^{\circ} \mathrm{C}$ for three minutes each. The relatively small shift at low annealing temperatures accelerates at higher temperatures leading to the highest blueshift of $34 \mathrm{~nm}$ ( $77 \mathrm{meV}$ disordering) at an annealing temperature of $950^{\circ} \mathrm{C}$. It was found that annealing the samples with $200 \mathrm{~nm} \mathrm{SiO}_{2}$ layers for 3 min even at $950{ }^{\circ} \mathrm{C}$ is not sufficient to obtain a considerable blueshift of the LOC laser diode structures. According to Kuzuhara et al [21], the degree of intermixing strongly depends on the thickness of the $\mathrm{SiO}_{2}$ together with the annealing temperature, hence, it was decided to increase the thickness of the $\mathrm{SiO}_{2}$ layer in order to obtain a higher degree of blueshift. Figure 1(b) illustrates the PL spectra dependence of QWI on $\mathrm{SiO}_{2}$ thickness on LOC HPLD structures annealed at $950{ }^{\circ} \mathrm{C}$ for three minutes. We found that under the same annealing conditions, the thicker the $\mathrm{SiO}_{2}$ layer, the larger the blueshift. The maximum blue shift of $55 \mathrm{~nm}(130 \mathrm{meV})$ was obtained in samples with $400 \mathrm{~nm}$ thick $\mathrm{SiO}_{2}$ layers. It is known that annealing for a longer duration with the same annealing temperature results in higher disordering of the effective band gap of the quantum well [28]. In order to understand the effects of the duration of annealing on QWI in HPLD structures, 1,2 and $3 \mathrm{~min}$ annealing at $950{ }^{\circ} \mathrm{C}$ with $400 \mathrm{~nm} \mathrm{SiO}_{2}$ overlayers was performed. Again, the maximum shift obtained after annealing for three minutes is $55 \mathrm{~nm}$. Figure 1(c) illustrates the PL spectra of QWI for a $400 \mathrm{~nm}$ $\mathrm{SiO}_{2}$ sputtered sample annealed at $950{ }^{\circ} \mathrm{C}$. A small difference in intermixing between 2 and 3 min annealing was observed ( $7 \mathrm{~nm}$ blue shift), thus it was considered unnecessary to anneal for longer durations. From these series of experiments, optimum annealing time, temperature and $\mathrm{SiO}_{2}$ thickness for QWI in LOC HPLD structures were determined as $3 \mathrm{~min}$, $950{ }^{\circ} \mathrm{C}$ and $400 \mathrm{~nm}$ thickness of $\mathrm{SiO}_{2}$, respectively.

Figure 2 illustrates the summary of the results of the PL data shown in figure 1 in terms of the shift of PL peak wavelength and the width of the PL peaks (FWHM). In figure 2(a) dependence of the PL shift on the annealing temperature shows an exponential behavior. It is well known that the atomic diffusion coefficients are exponentially dependent on the temperature [29]. FWHM variation of the 


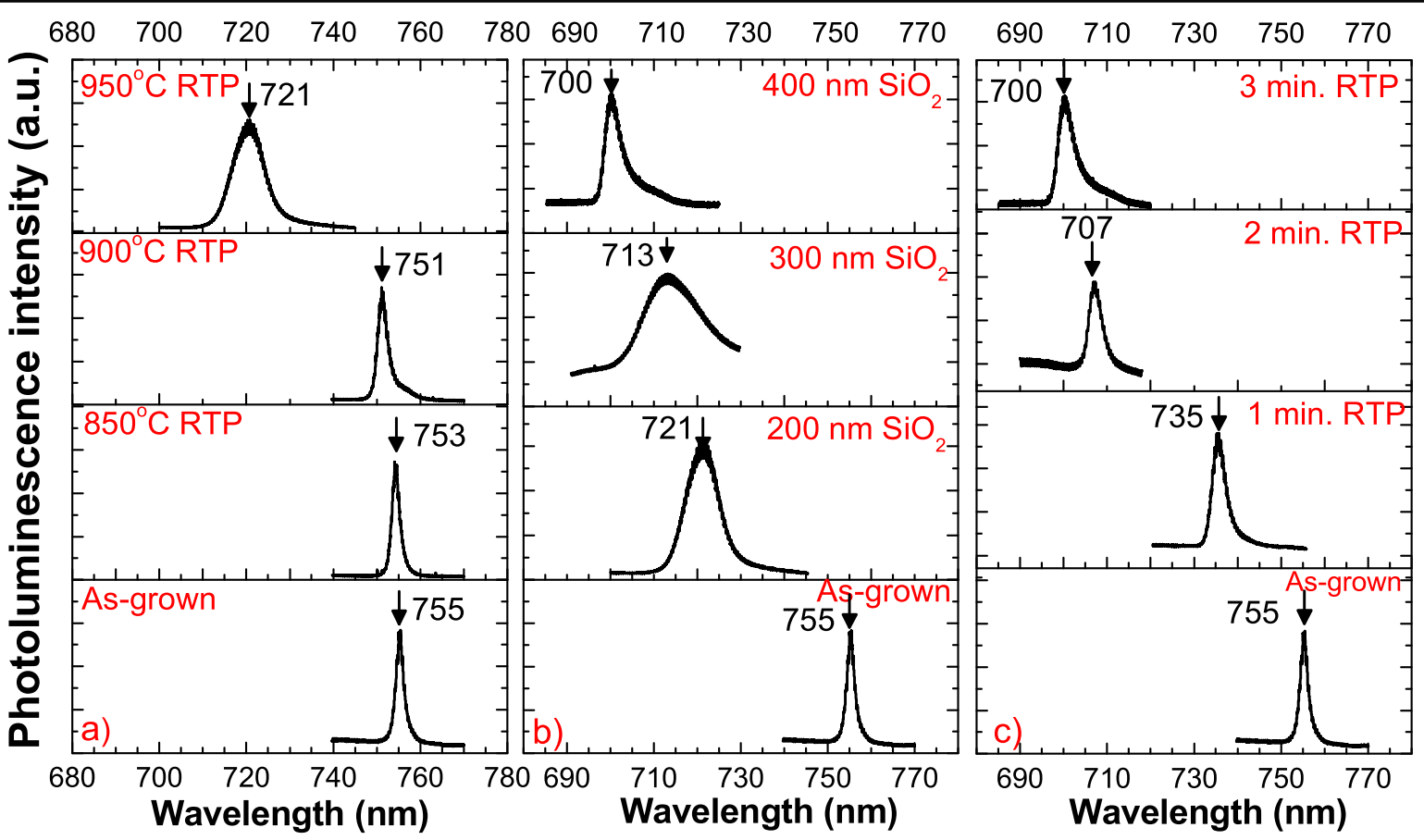

Figure 1. Photoluminescence spectra of HPLD dependence on (a) annealing temperature, (b) encapsulant thickness, and (c) annealing time.

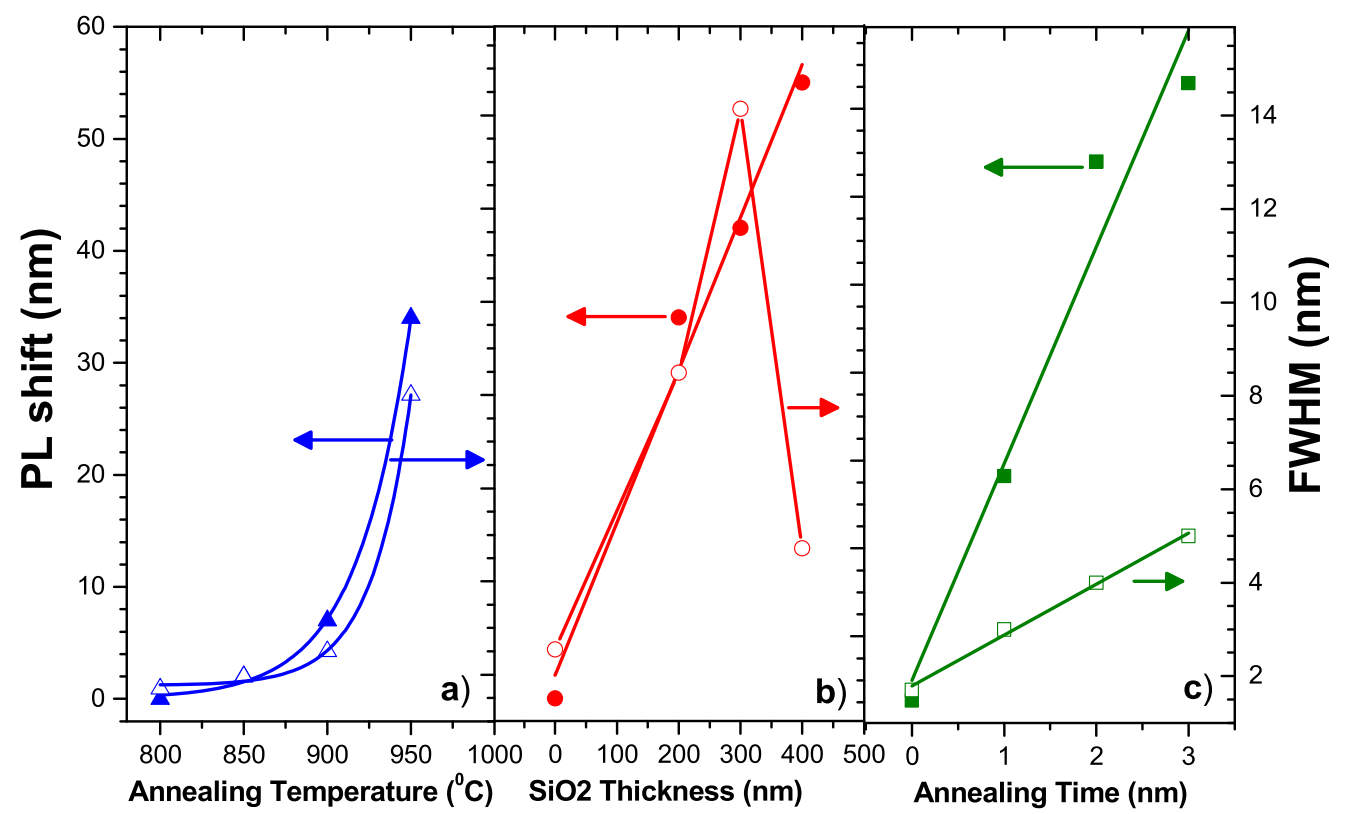

Figure 2. Left axis of the figure shows the PL shift while the right side of the figure shows the FWHM variation of the peaks. The left and right axis is common for parts a,b and c, PL shift and FWHM of the PL emission, respectively. The filled symbols in each figure correspond to the PL shift while the blank symbols to the PL width (FWHM) variation of the peaks. (a) Annealing temperature, (b) encapsulant thickness, (c) annealing time dependence of the PL shift and the broadening of the quantum well luminescence.

peak also follows an exponential variation. The exponential behavior of the degree of intermixing and hence the amount of blueshift can be understood when the exponential dependence of the diffusion coefficient on temperature is considered. With a constant prefactor and activation energy, higher annealing temperatures lead to exponentially larger diffusion coefficients that translate into longer diffusion lengths and hence to larger PL peak wavelength shifts. The dependence of the PL shift on the $\mathrm{SiO}_{2}$ overlayer thickness shows a linear dependence, see figure 2(b). The role of $\mathrm{SiO}_{2}$ in blueshifting of the bandgap luminescence is twofold. The first is related to the deposition conditions, hence sputtering generates point defects on the surface of the sample during the initial phase of deposition facilitating the diffusion of atomic species. The second function of the $\mathrm{SiO}_{2}$ layer is to act as a source of point defects and provide a sink for the out-diffusing atomic species with thicker $\mathrm{SiO}_{2}$ layers providing a larger sink for out-diffusion. The width of the PL peak is a 
measure of the spatial fluctuations of the quantum well potential. It increases with increasing spatial fluctuations. Contributions from locally varying quantum wells of different potential wells make up the PL peak. Close inspection shows that the width of the PL peak for the sample with $400 \mathrm{~nm}$ $\mathrm{SiO}_{2}$ (figure 2(b)), has seemingly two distinct contributions. In addition to the strong high energy peak, a low intensity wide tail suggests that the local variations of the potential are minimized. As the quantum well is quite narrow and is composed of a limited number of GaAs layers, dissolution of the layers creating point defects and interdiffusion of $\mathrm{Al}$ into GaAs can be considered to be discreet, hence it seems that the islands of newly created local potentials (due to diffusion of $\mathrm{Al}$ ) enlarging at the expense of the previously pristine sections of the same layers to produce a sharp blue-shifted peak along with a tail, originate from leftover virgin portions of the layer on the quantum well. Finally, figure 2(c) depicts the linear dependence of PL peak wavelength shift on annealing duration dependence. The FWHM of the luminescence peaks also shows linear dependence on the duration of annealing. Considering that the PL emission wavelength is proportional to the square of the width of the quantum well and that the diffusion length is proportional to the square root of time, the linear dependence of the PL shift on the duration of annealing is expected [29]. The linewidth of a PL peak is a function of crystalline disorder and therefore an increase in the width of the PL peaks with annealing time is also expected.

Suppression of QWI is as necessary as the enhancement of QWI because the band gap of the active waveguide region where the current is injected needs to be preserved during annealing for the QWI enhancement of the cavity edges in order to maintain the design wavelength. Thin films of thermally deposited $\mathrm{SrF}_{2}$ were successfully demonstrated to inhibit QWI [30]. In this study, $100 \mathrm{~nm}$ of thermally deposited $\mathrm{SrF}_{2}$ was used in order to suppress QWI in LOC HPLD structures, which is illustrated in figure 3. A maximum blueshift of $9 \mathrm{~nm}$ was observed in samples with $100 \mathrm{~nm} \mathrm{SrF} 2$ annealed for three minutes at $950{ }^{\circ} \mathrm{C}$. This is to be compared with the blueshift of $55 \mathrm{~nm}$ for the same duration of annealing and temperature. In this study, suppression of intermixing in a LOC laser diode structure, with a $2.35 \mu \mathrm{m}$ (cladding and waveguide) thick epitaxial overlayer between the quantum well and the surface, resulted in $9 \mathrm{~nm}$ disordering after $3 \mathrm{~min}$ of annealing at $950{ }^{\circ} \mathrm{C}$. This result is quite promising to prevent QWI in the active region of the HPLD structure.

Depth-resolved XPS analysis was used to understand the relationship between the luminescence peak wavelength shifts and diffusion of various elements in thermally processed samples using the IFVD mechanism, by comparing an asgrown sample and the sample that showed a $55 \mathrm{~nm}(130 \mathrm{meV})$ blue shift which was annealed with a $400 \mathrm{~nm} \mathrm{SiO}{ }_{2}$ sputtered layer at $950{ }^{\circ} \mathrm{C}$ for $3 \mathrm{~min}$. $\mathrm{Ga}, \mathrm{As}, \mathrm{Al}, \mathrm{Si}, \mathrm{O}$ and $\mathrm{C}$ were followed through $\mathrm{Ar}^{+}$depth profiling. XPS spectra were collected at each of the 35 sputtering intervals (cycles) to generate the depth profile. Figure 4 shows representative XPS plots for $\mathrm{Ga}\left(2 \mathrm{p}_{1 / 2}\right)$ and $\mathrm{Ga}\left(2 \mathrm{p}_{3 / 2}\right), \mathrm{Al}(2 \mathrm{p})$, and $\mathrm{As}(3 \mathrm{~d})$ lines of the elements for the processed sample. A detectable but small

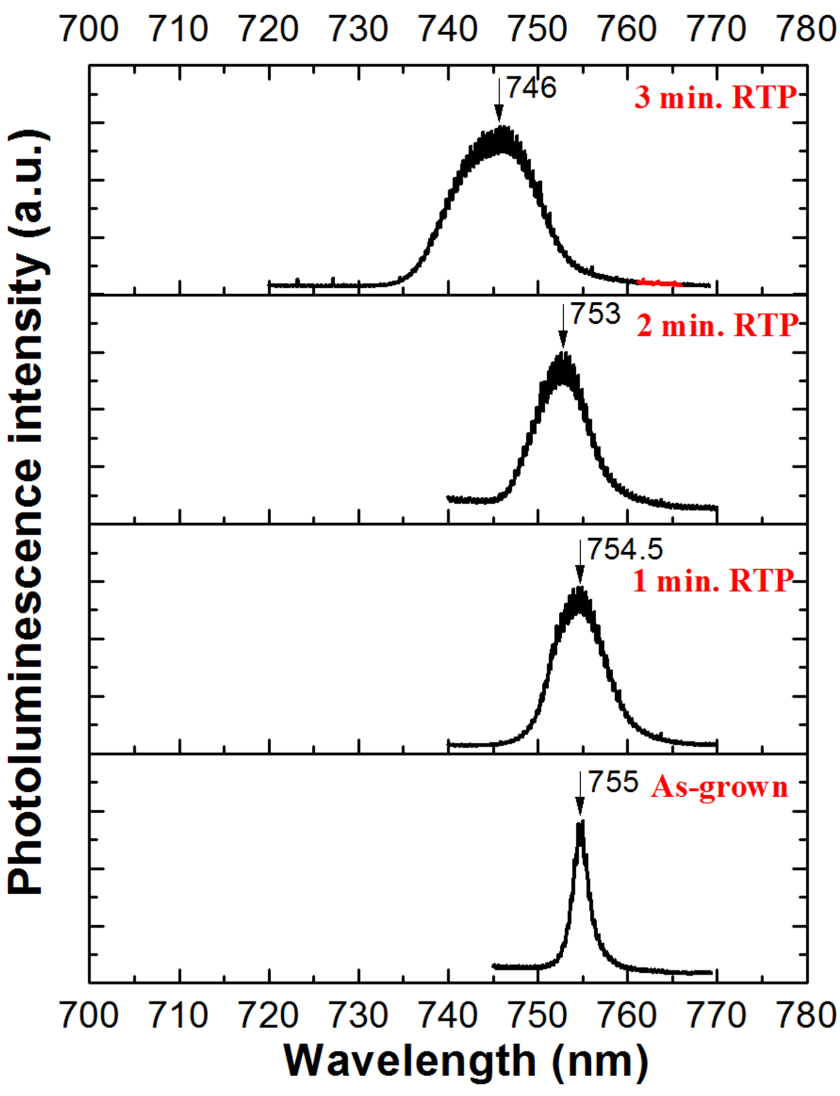

Figure 3. The effects of $\mathrm{SrF}_{2}$ layers on the photoluminescence spectrum.

amount of carbon contamination due to atmospheric exposure is observed on the surface of the samples. Carbon is observed in only the first sputter cycle with a binding energy of about $283.1 \mathrm{eV}$ which corresponds to $\mathrm{C}-\mathrm{C}$ binding (figure not shown).

The most significant element in the QWI of a GaAs/ AlGaAs crystal structures is $\mathrm{Ga}$, it being the principal migrating element during annealing. In XPS, Ga is typically monitored using $\mathrm{Ga}(2 \mathrm{p})$ either through $\mathrm{Ga}\left(2 \mathrm{p}_{1 / 2}\right)$ or $\mathrm{Ga}\left(2 \mathrm{p}_{3 / 2}\right)$ lines. In figure 4(a) we present the spectra for both $\mathrm{Ga}(2 \mathrm{p})$ peaks. Once most of the $\mathrm{SiO}_{2}$ layer is sputtered away, at about the 10th sputter cycle, $\mathrm{Ga}(2 \mathrm{p})$ peaks appear with binding energies of $1116.8 \mathrm{eV}$ and $1143.7 \mathrm{eV}$ which are associated with $\mathrm{Ga}\left(2 \mathrm{p}_{3 / 2}\right)$ and $\mathrm{Ga}\left(2 \mathrm{p}_{1 / 2}\right)$ lines, respectively (see figure 4(a)). The integrated peak intensity of the Ga 2 p $3 / 2$ and the Ga $2 \mathrm{p} 1 / 2$ becomes generally different and the ratio is Ga 2 p $3 / 2$ to Ga $2 p 1 / 2$ is generally given by 2 [31]. This is related to occupancy of the levels split, 2 p $3 / 2$ and 2 p $1 / 2$ due to the spin-orbit coupling. The integrated intensity ratio of the obtained $\mathrm{Ga} 2 \mathrm{p} 3 / 2$ and $1 / 2$ is 2.002 which is theoretically what it is expected. A $\operatorname{As}(3 \mathrm{~d})$ spectrum of the intermixed sample appears at the 10th sputter cycle where $\mathrm{O}(1 \mathrm{~s})$ and $\mathrm{Si}(2 \mathrm{p})$ peaks start to disappear corresponding to the end of the $\mathrm{SiO}_{2}$ layer (figure 5). Details of the figure will be given in the next paragraph. The XPS peak for arsenic is acquired for $\mathrm{As}(3 \mathrm{~d})$ photoelectrons and $\mathrm{GaAs}, \mathrm{As}_{2} \mathrm{O}_{3}, \mathrm{GaAs}$ native oxide, both triple and quintuple charged As, are the common chemical states for As(3d) lines. The As(3d) binding 

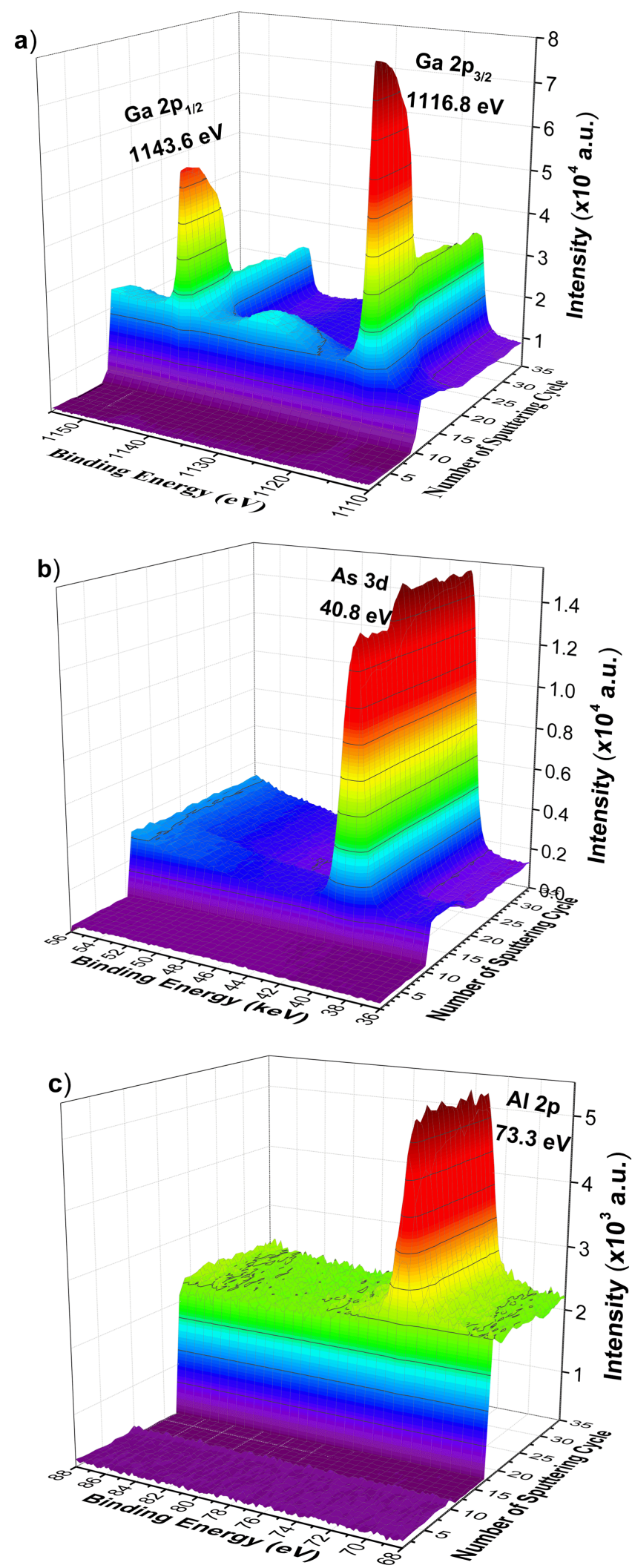

Figure 4. Spectral surfaces of depth-resolved XPS data, (a) $\mathrm{Ga}\left(2 \mathrm{p}_{1 / 2}\right)$ and $\mathrm{Ga}\left(2 \mathrm{p}_{3 / 2}\right)$, (b) $\mathrm{As}(3 \mathrm{~d})$ and (c) $\mathrm{Al}(2 \mathrm{p})$ lines of the quantum well intermixed samples. The soft wide peak in (a) is the plasmon loss peak. Note that the peak positions do not change with depth, indicating no change in the chemical environment of the species throughout the sample. energies for these chemical states are $40.8 \mathrm{eV}, 44.1 \mathrm{eV}$, $44.8 \mathrm{eV}$ and $45.6 \mathrm{eV}$, respectively [32]. In our data the binding energy of $\mathrm{As}(3 \mathrm{~d})$ is observed at $40.8 \mathrm{eV}$ corresponding to GaAs as expected, see figure 4(b). Figure 4(c) shows the $\operatorname{Al}(2 \mathrm{p})$ spectrum of the intermixed sample starting at the 18th sputter cycle where the AlGaAs cladding layer is placed. Most common chemical states of $\mathrm{Al}(2 \mathrm{p})$ are $\mathrm{Al}$ metal $(72.6 \mathrm{eV})$, aluminosilicate $(74.4 \mathrm{eV}), \mathrm{Al}$-oxide $(74.6 \mathrm{eV})$ and Al-foil $(75.6 \mathrm{eV})$. It is clear that the peak in the figure observed at $73.3 \mathrm{eV}$ corresponds to the metallic state of Al.

Depth distribution of the relevant atomic species for both as-grown as well as thermally processed samples are shown in figure 5. The data demonstrates diffusion of $\mathrm{Ga}$ atoms towards the surface which results in interdiffusion of $\mathrm{Ga}$ vacancies towards the quantum well region. After XPS analysis, the depth profile of the sputtered crater was measured using a Dektak surface profilometer which is shown as an inset in figure 5. According to this data, the depth profile can be divided into three regions; the first region is the $400 \mathrm{~nm}$ encapsulated $\mathrm{SiO}_{2}$ layer, the second region is the $500 \mathrm{~nm}$ GaAs cap layer and the third is approximately $900 \mathrm{~nm}$ of the AlGaAs cladding layer. The demonstration of intermixing is described by comparing the as-grown sample with the intermixed sample. In the second region, where the GaAs cap layer is located, we observe that both $\mathrm{Ga}$ and As concentrations deviate from stoichiometry and are Ga-enriched in both the intermixed and as-grown samples. This is the well-known preferential sputtering effect [33], which explains the observed Ga-enriched region. Fortunately, a comparison of the as-grown and intermixed samples is still possible. In the second and third regions, Ga concentration in the intermixed sample is higher than the as-grown sample which shows the migration of $\mathrm{Ga}$ atoms away from active region and the AlGaAs waveguide layer, towards the surface. The ratio of $\mathrm{Ga}(2 \mathrm{p})$ concentration in the intermixed and as-grown samples is 1.24. A similar behavior holds also for the $\mathrm{Al}$ concentration profile. This is direct evidence of the diffusion of $\mathrm{Al}$ and $\mathrm{Ga}$ atoms due to thermal treatment. Diffusion of $\mathrm{Al}$ from the AlGaAs cladding layer into the GaAs cap layer is also clearly observed. The amount of $\mathrm{Al}$ in the second region reaches almost to 5\% upon thermal treatment where it previously did not exist, even to the point of penetrating into the $\mathrm{SiO}_{2}$ layer.

Finally, the amount of As decreases upon thermal treatment in both the second and third regions. In addition to the changes in the concentrations of $\mathrm{Ga}$, we note that the $\mathrm{Ga}$ profile for the intermixed sample shifts towards the surface at the AlGaAs/GaAs interface, a clear indication of Ga migration towards the surface. However, expected observation of $\mathrm{Ga}$ atoms throughout the encapsulant layer $\left(\mathrm{SiO}_{2}\right)$ has not been realized. Instead, a small percentage of $\mathrm{Ga}$ atoms diffuses into the $\mathrm{SiO}_{2}$ and $\mathrm{GaAs}$ cap layer rapidly decaying towards the surface, see figure 5. There might be several reasons for this. First, as reported in [25], the small amount of $\mathrm{Ga}$ in the $\mathrm{SiO}_{2}$ layer can only be recognized with Auger electron spectroscopy which we did not utilize. Second, in such LOC HPLD structures (table 1), for short periods of 


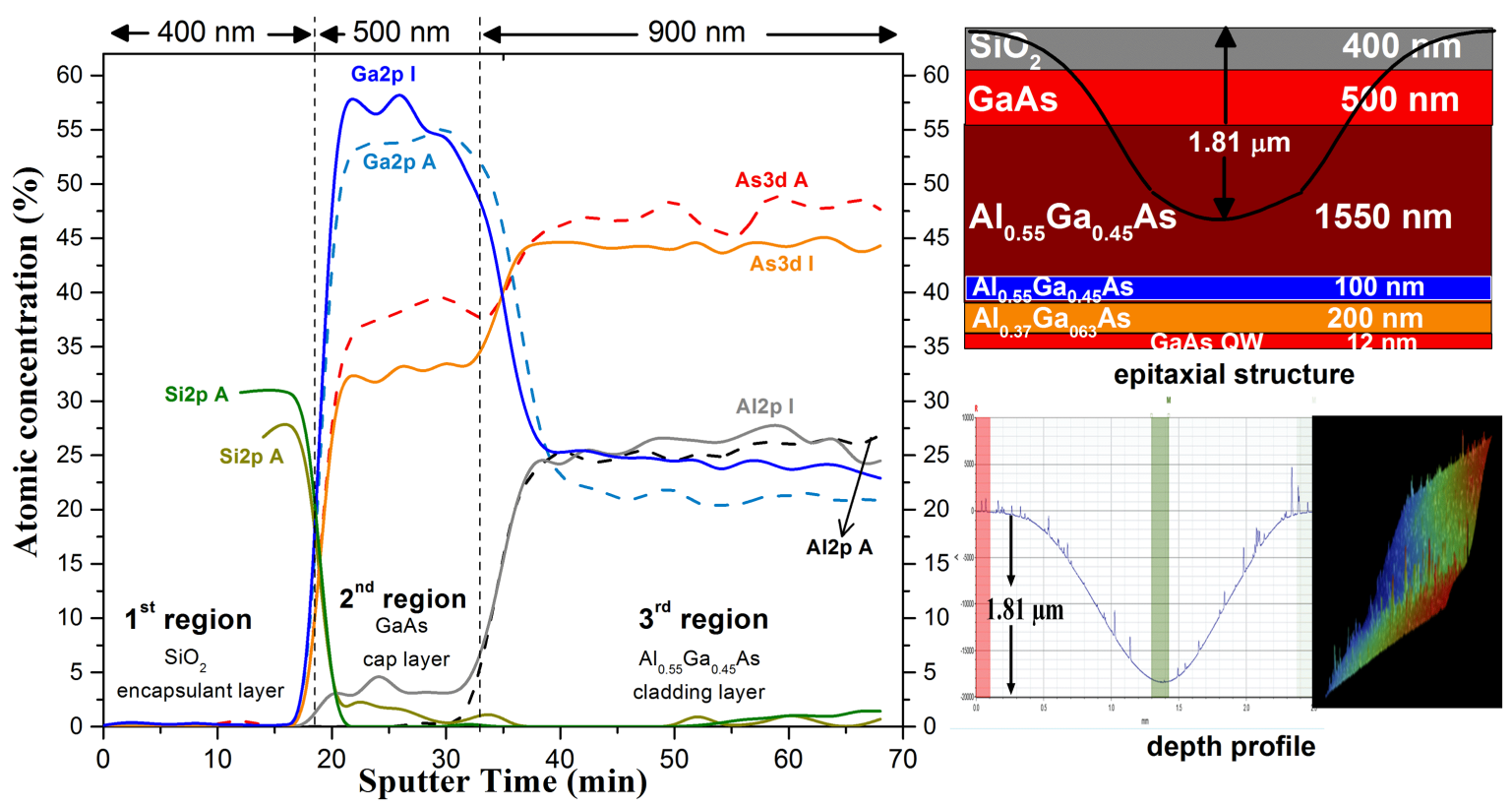

Figure 5. XPS depth profile of an intermixed and as-grown sample. The inset in the right side top of the plot shows the epitaxial layers up to the GaAs QW of the grown high power laser diode structure. It shows the depth performed in the XPS measurement. The inset at the right side bottom is the three-dimensional depth profile of the sputtered crater after the XPS measurements have been done. The obtained depth is $1.81 \mu \mathrm{m}$ for the as-grown and $1.83 \mu \mathrm{m}$ (not shown) for the intermixed sample. The abbreviations used in the figure 'I' mean intermixed, 'A' as-grown.

annealing and annealing temperatures performed in this study, Ga atoms may not have had time to penetrate throughout all of the $\mathrm{SiO}_{2}$ layer. XPS results obtained in the present study shows that $\mathrm{Ga}$ and $\mathrm{Al}$ diffusion throughout the thermally processed LOC samples correlates well with the observed PL peak shifts indicating successful QWI in LOC HPLD structures at relatively low temperatures and durations.

\section{Conclusions}

HPLDs are performance limited during lasing due mainly to COMD. Use of quantum well intermixing to create NAM regions at the cavity edges and using LOC are the main solutions in order to minimize COMD. The optimum conditions for the IFVD technique for both enhancement and suppression of QWI in actual LOC laser diode structures in an $\mathrm{AlGaAs} / \mathrm{GaAs}$ structure have been determined and correlated with $\mathrm{Ga}$ and $\mathrm{Al}$ diffusion using both low temperature PL spectroscopy and XPS depth profiling for the first time. AlGaAs/GaAs LOC HPLD structures were used where the quantum well was buried $2.35 \mu \mathrm{m}$ below the surface (without the encapsulating layer), typical for LOC cavities. A $55 \mathrm{~nm}$ $(130 \mathrm{meV})$ blueshift in the PL peak due to QWI and only $9 \mathrm{~nm}(19.8 \mathrm{meV})$ blueshift during suppression of QWI, respectively, were obtained at $950{ }^{\circ} \mathrm{C}$ for $3 \mathrm{~min}$ in a RTP. XPS analysis shows migration of $\mathrm{Ga}$ and $\mathrm{Al}$ atoms towards the surface correlating with the observed blueshift.

\section{Acknowledgments}

The authors would like to thank Professor Dr Raşit Turan and İlker Yildız of METU Central laboratory for XPS data acquisition. The financial support of Ermaksan A S is gratefully acknowledged.

\section{References}

[1] Henry C H, Petroff P M, Logan R A and Merritt F R 1979 J. Appl. Phys. 50 3721-32

[2] Marsh J H 2007 Laser Technik J. 4 32-5

[3] Hempel M, Tomm J W, Ziegler M, Elsaesser T, Michel N and Krakowski M 2010 Appl. Phys. Lett. 97231101

[4] Diechl R 2000 High-Power Diode Lasers: Fundamentals, Technology, Applications (Germany: Springer)

[5] Alferness R C, Koren U, Buhl L L, Miller B I, Young M G, Koch T L, Raybon G and Burrus C A 1992 Appl. Phys. Lett. 60 3209-11

[6] Morita T, Nagakura T, Torii K, Takauji M, Maeda J, Miyamoto M, Miyajima $\mathrm{H}$ and Yoshida $\mathrm{H} 2013$ IEEE J. Sel. Top. Quantum Electron. 191502104

[7] Marsh J H 1993 Semicond. Sci. Technol. 8 1136-55

[8] Epperlein P W 2013 Semiconductor Laser Engineering, Reliability and Diagnostics: A Practical Approach to High Power and Single Mode Devices (UK: Wiley)

[9] Wen X, Chi J Y, Koteles E S, Elman B and Melman P 1990 J. Electron. Mater. 19 539-42

[10] Yu J S and Chung K S 2007 Semicond. Sci. Technol. 22 919-24

[11] Du S C, Fu L, Tan H H and Jagadish C 2010 Semicond. Sci. Technol. 25055014 
[12] Helmy A S, Murad S K, Bryce A C, Aitchison J S, Marsh J H, Hicks S E and Wilkinson C D W 1999 Appl. Phys. Lett. 74 $732-4$

[13] Deenapanray P N K, Tan H H, Cohen M I, Gaff K, Petravic M and Jagadish C 2000 J. Electrochem. Soc. 147 1950-6

[14] Deenapanray P N K and Jagadish C 2001 J. Vac. Sci. Technol. B 19 1962-6

[15] Rao E V K, Hamoudi A, Krauz P, Juhel M and Thibierge H 1995 Appl. Phys. Lett. 66 472-4

[16] Pepin A, Vieu C, Schneider M, Launois H and Nissim Y 1997 J. Vac. Sci. Technol. B 15 142-53

[17] Doshi S, Deenapanray P N K, Tan H H and Jagadish C 2003 J. Vac. Sci. Technol. B 21 198-203

[18] Kowalski O P, Hamilton C J, McDougall S D, Marsh J H, Bryce A C, De La Rue R M, Vgele B, Stanley C R, Button C C and Roberts J S 1998 Appl. Phys. Lett. 72 $581-3$

[19] Allen E L, Pass C J, Deal M D, Plummer J D and Chia V F K 1991 Appl. Phys. Lett. 59 3252-4

[20] Gonjito I, Krauss T, Marsh J H and De La Rue R M 1994 IEEE J. Quantum Electron. 30 1189-95

[21] Kuzuhara M, Nozaki T and Kamejima T 1989 J. Appl. Phys. $665833-6$
[22] Matsushita S, Terada S, Fujii E and Harada Y 1993 Appl. Phys. Lett. $63225-7$

[23] Gyulai J, Mayer J, Mitchell I V and Rodriguez V 1970 Appl. Phys. Lett. 17 332-4

[24] Haga T, Tachino N, Abe Y, Kasahara J, Okubora A and Hasegawa H 1989 J. Appl. Phys. 66 5809-15

[25] Konig U and Sasse E 1983 J. Electrochem. Soc. 130 950-2

[26] Fu L et al 2002 J. Appl. Phys. 92 3579-83

[27] Hofstetter D, Maisenholder B and Zappe H P 1998 IEEE J. Sel. Top. Quantum Electron. 4 794-802

[28] Ooi B S, McIlvaney K, Street M W, Helmy A S, Ayling S G, Bryce A C and Marsh J H 1997 IEEE J. Quantum Electron. 33 1784-92

[29] Lie J T 2000 Semiconductor Quantum Well Intermixing: Material Properties and Optoelectronic Applications (Singapore: Gordon and Breach Science) ch 2

[30] Beauvais J, Marsh J H, Kean A H, Bryce A C and Button C 1992 Electron. Lett. 28 1670-2

[31] Colón Santana J A 2015 Quantitative Core Level Photoelectron Spectroscopy (CA, USA: Morgan \& Claypool)

[32] Crist B V 2000 Handbooks of Monochromatic XPS Spectra (UK: Wiley)

[33] Singer I L, Murday J S and Comas J 1981 J. Vac. Sci. Technol. 18 161-3 